\title{
Characterization of two heparan sulphate-binding sites in the mycobacterial adhesin HIp
}

\author{
Michelle I Portugal ${ }^{1}$, Adriane R Todeschini ${ }^{2}$, Cristiana S de Lima1, \\ Carlos AM Silva1, Ronaldo Mohana-Borges ${ }^{3}$, Tom HM Ottenhoff ${ }^{4}$, \\ Lucia Mendonça-Previato ${ }^{2}$, Jose O Previato ${ }^{2}$ and Maria CV Pessolani*1
}

\begin{abstract}
Address: ${ }^{1}$ Laboratório de Microbiologia Celular, Instituto Oswaldo Cruz, FIOCRUZ, Av. Brasil 4365, Manguinhos, Rio de Janeiro, RJ 21045-900, Brazil, ${ }^{2}$ Laboratório de Glicobiologia, Instituto de Biofísica Carlos Chagas Filho, Universidade Federal do Rio de Janeiro, Av. Brigadeiro Tropowsky, Rio de Janeiro, RJ, 21949-900, Brazil, ${ }^{3}$ Laboratório de Genomica Estrutural, Instituto de Biofísica Carlos Chagas Filho, Universidade Federal do Rio de Janeiro, Av. Brigadeiro Tropowsky, Rio de Janeiro, RJ, 21949-900, Brazil and ${ }^{4}$ Department of Immunohematology and Blood Transfusion, Leiden University Medical Center, Building 1 E3-Q, P.O. box 9600, 2300 RC - Leiden, The Netherlands

Email: Michelle I Portugal - michelleip@ig.com.br; Adriane R Todeschini - adrianet@biof.ufrj.br; Cristiana S de Lima - crislima@ioc.fiocruz.br; Carlos AM Silva - adrianoc5@hotmail.com; Ronaldo Mohana-Borges - mohana@biof.ufrj.br; Tom HM Ottenhoff - T.H.M.Ottenhoff@lumc.nl; Lucia Mendonça-Previato - luciamp@biof.ufrj.br; Jose O Previato - previato@biof.ufrj.br; Maria CV Pessolani* - cpessola@ioc.fiocruz.br

* Corresponding author
\end{abstract}

Published: 15 May 2008

BMC Microbiology 2008, 8:75 doi:10.1186/147I-2180-8-75
Received: 4 October 2007

Accepted: 15 May 2008

This article is available from: http://www.biomedcentral.com/I47/-2/80/8/75

(c) 2008 Portugal et al; licensee BioMed Central Ltd.

This is an Open Access article distributed under the terms of the Creative Commons Attribution License (http://creativecommons.org/licenses/by/2.0), which permits unrestricted use, distribution, and reproduction in any medium, provided the original work is properly cited.

\begin{abstract}
Background: The histone-like Hlp protein is emerging as a key component in mycobacterial pathogenesis, being involved in the initial events of host colonization by interacting with laminin and glycosaminoglycans (GAGs). In the present study, nuclear magnetic resonance (NMR) was used to map the binding site(s) of Hlp to heparan sulfate and identify the nature of the amino acid residues directly involved in this interaction.

Results: The capacity of a panel of 30 mer synthetic peptides covering the full length of Hlp to bind to heparin/heparan sulfate was analyzed by solid phase assays, NMR, and affinity chromatography. An additional active region between the residues $\mathrm{Gly} 46$ and Ala60 was defined at the $\mathrm{N}$-terminal domain of Hlp, expanding the previously defined heparin-binding site between Thr3I and Phe50. Additionally, the C-terminus, rich in Lys residues, was confirmed as another heparan sulfate binding region. The amino acids in Hlp identified as mediators in the interaction with heparan sulfate were Arg, Val, lle, Lys, Phe, and Thr.

Conclusion: Our data indicate that Hlp interacts with heparan sulfate through two distinct regions of the protein. Both heparan sulfate-binding regions here defined are preserved in all mycobacterial Hlp homologues that have been sequenced, suggesting important but possibly divergent roles for this surface-exposed protein in both pathogenic and saprophic species.
\end{abstract}

\section{Background}

Leprosy and tuberculosis constitute age-old infectious diseases that have affected human beings for millennium. Leprosy, caused by Mycobacterium leprae, continues to be a significant public health problem in several developing countries, including Brazil, and is responsible for the legacy of millions of individuals with permanent physical deformities [1]. On the other hand, tuberculosis, caused 
by Mycobacterium tuberculosis has most likely killed more human beings than any other disease in history, at an average of 4 individuals per minute worldwide [2]. One major reason for the failure to eradicate these diseases may be closely related to the absence of effective vaccines since BCG, the only one available against both leprosy and tuberculosis, has displayed highly variable protection rates around the world [3]. Mycobacteria are intracellular pathogens that preferentially infect mononuclear phagocytes although other cell types such as epithelial and endothelial cells are also colonized during disease dissemination [4]. M. leprae, also found inside Schwann cells of the peripheral nervous system, is responsible for the nerve damage observed in leprosy [5]. Mycobacteria are Grampositive bacteria presenting a very complex and unique cell wall structure, which seems to play a major role in their pathogenesis. Deciphering the mechanisms implicated in mycobacterial pathogenesis remains a major challenge for leprosy and tuberculosis research, which will hopefully lead to the development of new, more effective prophylactic and/or therapeutic strategies.

During infection, a critical early event is the adherence of the microorganism to the target tissues within the host. Adhesion is accomplished by specific molecular interactions involving adhesins on the bacterial surface and receptors on the surface of the host cell. The histone-like Hlp protein is a positively-charged, surface-exposed molecule recently implicated in the attachment of pathogenic mycobacteria to host cells. This protein was initially described as a laminin-binding protein (LBP) involved in M. leprae-Schwann cell interaction. [6,7]. More recently Hlp has been shown to also play a major role in mediating the adhesion of mycobacteria to epithelial respiratory cells by interacting with proteoglycan-containing receptors such as heparan sulfate and hyaluronic acid $[8,9]$.

Mycobacterial Hlp, roughly twice the size of other bacterial histone-like proteins, is a highly conserved protein shared by all mycobacterial species. The $\mathrm{N}$-terminal half of mycobacterial Hlp containing the prokaryotic DNAbinding motif shares significant homology with the histone-like HU proteins found in Escherichia coli and the HB proteins in Bacillus subtilis, respectively. The C-terminal half of mycobacterial Hlp, absent in most bacteria, has an unusual amino acid composition owing to a high alanine, lysine, and proline content resembling the C-terminal region of eukaryotic class $\mathrm{H} 1$ histones [10]. Initial studies by Aoki et al [9] have mapped the heparin-binding site of Hlp (so-called MDP1) in the N-terminal region between Thr31 and Phe50 overlapping the previously defined DNA-binding region [11]. However, after testing the truncated recombinant Hlp molecules corresponding to the $\mathrm{N}$-terminal (rHlp-N) and the C-terminal (rHlp-C) domains of the protein, we recently found that the inter- action of Hlp/LBP with laminin and heparin was for the most part mediated by the C-terminal domain of the protein. Moreover, the same domain was found to be involved in Hlp/LBP-mediating bacterial binding to human Schwann cells [12]. It is clear that additional studies are needed to more precisely define the interacting regions of Hlp/LBP with glycosaminoglycans (GAG).

In the present report, the interaction of Hlp with heparan sulfate was further investigated by using a panel of 30-mer synthetic peptides covering the full length of the protein and nuclear magnetic resonance (NMR). The resulting data indicate that Hlp interacts with heparan sulfate through two distinct regions located, respectively, in the $\mathrm{N}$-terminal and C-terminal domains of the protein.

\section{Results \\ Binding of Hlp synthetic peptides to heparan sulfate}

In a previous study, truncated recombinant Hlp molecules were tested and it was demonstrated that the highly positive C-terminal region of the protein is involved in its binding to extracellular matrix components and its capacity to act as an adhesin [12]. To refine and confirm these data, a panel of overlapping 30-mer synthetic peptides covering the entire sequence of Hlp was immobilized in microtiter-plate wells. The peptides were, then, incubated with biotinylated heparin or heparan sulfate in phosphate buffer $10 \mathrm{mM} \mathrm{pH} 7.2$ and their binding capacity was monitored by the addition of streptavidin peroxidase. The list of Hlp peptides with their corresponding amino acid sequences and $\mathrm{pI}$ shown in Table 1. As shown in Figure $1 \mathrm{~A}$, heparan sulfate bound to peptides covering the C-terminal region of the protein. Among the peptides derived from the N-terminal region, detectable binding of biotinylated heparan sulfate was only observed in wells coated with p31-60 and p46-75. Although the signal with these peptides was low, this was a consistent result observed in six independent experiments. An identical binding pattern was observed when biotinylated heparin was used instead of heparan sulfate (data not shown). The binding of the peptides covering the $\mathrm{C}$-terminal region is in agreement with previous results demonstrating that rHlp-C (from Ala110 to Lys200), but not rHlp-N (covering the first 109 Hlp amino acids), was able to bind heparan sulfate in a similar solid-phase assay [12]. Moreover, the binding of p31-60 is in agreement with the Hlp heparinbinding region between Thr 31 and Phe50 defined by Aoki et al, 2004 [9]. However, the binding of p46-75 suggested an additional binding region.

\section{Effect of salt concentrations on the binding of HIp peptides to heparan sulfate in microplate assays}

All peptides that showed heparan sulfate-binding activity are rich in basic amino acid residues. To investigate whether Hlp-heparin/heparan sulfate interactions are 

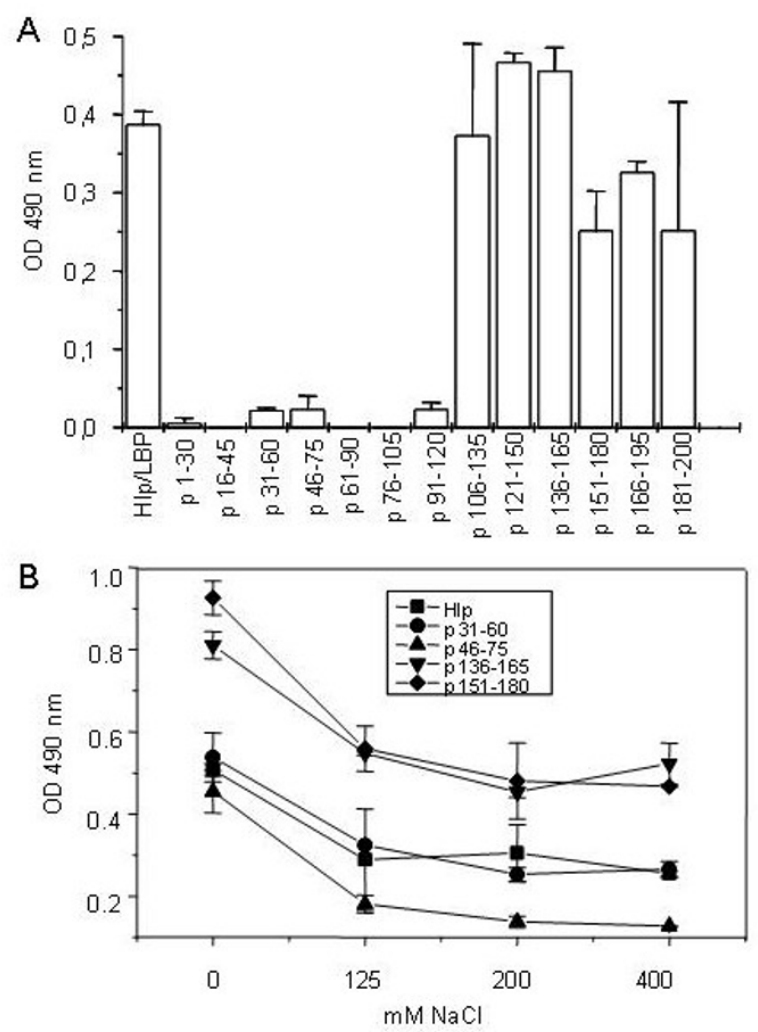

Figure I

Hlp peptides corresponding to the C-terminal domain bind heparan sulfate. (A) Microtiter-plate wells coated with $50 \mu \mathrm{L}$ of $0.1 \mu \mathrm{M}$ HIp or $50 \mu \mathrm{L}$ of $0.65 \mu \mathrm{M}$ individual 30-mer synthetic peptides covering the entire sequence of Hlp were incubated with biotinylated heparan sulfate in phosphate buffer $10 \mathrm{mM}$, pH 7.2. Heparan sulfate binding was measured by adding streptavidin peroxidase to the wells and expressed in absorbency units at $490 \mathrm{~nm}$. The data are expressed as mean $\pm S D$ of a representative experiment from five independent ones performed in duplicate. (B) Microtiter-plate wells were coated with Hlp or peptides p3I-60, p I36-165, and pI5I-180 and biotinylated heparan sulfate was added in the presence of increasing concentrations of $\mathrm{NaCl}$. Heparan sulfate binding was quantified as above.

mediated by electrostatic forces involving the negatively charged sulfate and carboxyl groups of heparin and heparan sulfate with the positively charged residues of Hlp, binding assays were performed in the presence of increasing concentrations of $\mathrm{NaCl}$. As can be seen in Figure $1 \mathrm{~B}$, for p31-60, p46-75, p136-165, and p151-180 and the entire Hlp protein, significant binding inhibition was achieved with increasing concentrations of $\mathrm{NaCl}$, indicating the involvement of electrostatic forces in these interactions.

\section{Binding of $p 3 I-60, p / 36-165$, and $p / 5 I-180$ to heparin- Sepharose}

The binding capacity of p31-60, p136-165, and p151180 was also analyzed by affinity chromatography on a column of heparin-Sepharose. Individual peptides were applied to a heparin-Sepharose column and subsequently eluted with a 0-2 $\mathrm{M} \mathrm{NaCl}$ gradient. Figure 2 shows the elution profile and the salt concentration necessary for elution of each peptide. Peptides p31-60, p36-165, and p151-180 bound to the column and were eluted at 1.09, 1.31 , and $1.29 \mathrm{M} \mathrm{NaCl}$, respectively, confirming their heparin-binding capacity.

\section{Analysis of the interaction of HIp peptides with heparan sulfate by STD-NMR}

To further elucidate the basis of Hlp and glycosaminoglycan interaction, the complexes between the peptides p1645, p31-60, p46-75, p136-165, p151-180, and heparan sulfate were studied using Saturation Transfer difference (STD)-NMR experiments. This technique allows for the identification of protons from a ligand molecule in contact with a macromolecule. Resonances of the oligosaccharide were selectively saturated and the spectrum was subtracted from a reference spectrum from which the heparan sulfate was not saturated. Lastly, the enhancements were observed in the difference (STD) spectrum $[13,14]$. Protons of the ligand peptide, which were in close contact with heparan sulfate, received the highest degree of saturation and were easily identified within the STD spectrum.

NMR experiments confirmed the heparan-sulfate binding capacity of p31-60, p46-75, p136-165, p51-180, and the inability of p16-45 to do so. Figure 3 shows the reference TOCSY spectrum (Figure 3A) of heparan sulfate (100 $\mu \mathrm{g})$ in the presence of $2 \mathrm{mM}$ p16-45. The difference in the Total Correlation Spectroscopy - (TOCSY)-STD spectrum obtained (Figure 3B) shows no signal, indicating that peptide p16-45 does not bind to heparan sulfate, thus providing a negative control with no specific interaction with the macromolecule. Nevertheless, Figure 4 shows a clear interaction between peptide p31-60 and heparan sulfate. Figure $4 \mathrm{~A}$ shows the cross peaks of the ligand protons involved in the formation of the complex. A close analysis of the STD spectrum shows a correlation among the $\delta \mathrm{H}$ at $3.18 \mathrm{ppm}, \beta \mathrm{H}$ and $\gamma \mathrm{H}$ at 1.85 , and $1.65 \mathrm{ppm}$, respectively, suggesting that at least one of the Arg residues is in close contact with heparan sulfate. In addition, it is evident that the magnetization is also transferred to the $\gamma \mathrm{CH}_{3}$ of Val. Figure $4 \mathrm{~B}$ provides evidence of the interaction of Phe residues with heparan sulfate. From the cross peaks at 3.19, $3.22 \mathrm{ppm}(\delta \mathrm{H})$ and those at $1.89(\beta \mathrm{H})$ and $1.63 \mathrm{ppm}(\gamma \mathrm{H})$ assigned in Figure $4 \mathrm{C}$, it is evident that heparan sulfate binds to the Arg (R) residues of p46-75. The interaction of the amino acid Val (V) is evidenced by signals at 0.89 
Table I: Amino acid sequence and pl values of Hlp synthetic peptides. Basic amino acids are in bold.

\begin{tabular}{|c|c|c|}
\hline Peptide & Amino acid sequence & pl \\
\hline pl & IMNKAELIDVLTQKLGSDRRQATAAVENVVD³0 & 5.00 \\
\hline p2 & 16SDRRQATAAVENVVDTIVRAVHKGDSVTIT45 & 6.48 \\
\hline p3 & 31TIVRAVHKGDSVTITGFGVFEQRRRAARVA60 & 11.83 \\
\hline p4 & ${ }^{46}$ GFGVFEQRRRAARVARNPRTGETVKVKPTS75 & $|2.0|$ \\
\hline p5 & ${ }^{6}$ RNPRTGETVKVKPTSVPAFRPGAQFKAVVA 90 & 11.73 \\
\hline p6 & 76VPAFRPGAQFKAVVAGAQRLPLEGPAVKRG 105 & 11.72 \\
\hline p7 & 9'GAQRLPLEGPAVKRGVATSAAKKAAIKKAPI20 & 11.22 \\
\hline p8 & 106УATSAAKKAAIKKAPVKKALAKKAATKAPA'135 & 10.90 \\
\hline p9 & 12IVKKALAKKAАTKAРАККАУKAРАKKITTAVI50 & 10.95 \\
\hline plo & 136КKАУKАРАККІТTАУКУРАККАТKУVККУА 165 & 11.00 \\
\hline pll & 15!KVPAKKATKVVKKVAAKAPVRKATTRALAK 180 & 10.70 \\
\hline pl2 & 166AKAPVRKATTRALAKKAAVKKAPAKKVTAA 195 & 12.06 \\
\hline p 13 & 181KAAVKKAPAKKVTAAKRGRK200 & 12.05 \\
\hline
\end{tabular}

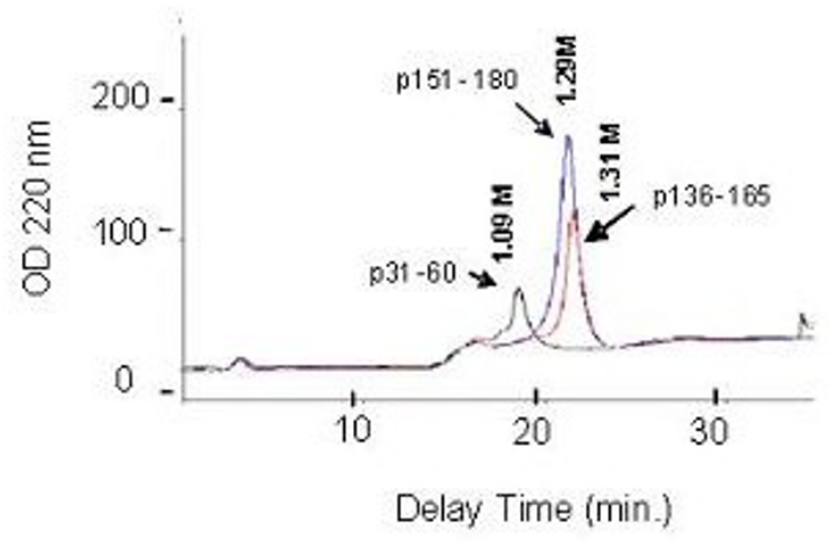

Figure 2

Elution profiles of $\mathrm{p} 3 \mathrm{I}-60, \mathrm{p} \mid 36-165$, and $\mathrm{p}|5|-\mid 80$ from a Heparin-Sepharose affinity colunm. Individual peptides bound to the column were eluted with a $0-2 \mathrm{M}$ gradient of $\mathrm{NaCl}$. Peptides p3 I-60, p I36-165, and p I5I-I80 were eluted, respectively, at I.09, I.3I, and I.29 M NaCl.

and $1.41 \mathrm{ppm}$. Furthermore, the interaction of at least one of the Thr (T) residues is evidenced by the resonances arising from $\gamma \mathrm{CH}_{3}$ (1.29 ppm), $\beta \mathrm{H}(3.96 \mathrm{ppm})$, and $\alpha \mathrm{H}(4.15$ ppm).

Figure 5A shows that the peptide p136-165 binds to heparan sulfate. The STD spectrum demonstrates that the amino acids involved in contact with the macromolecule were Lys $(3.02,2.99,1.73$, and 1.38 ppm), and the hydrophobic residue Ile146 $(\gamma \mathrm{CH} 3,0.96 \mathrm{ppm}$, and $\gamma \mathrm{H}, 1.23$ and $1.38 \mathrm{ppm}$ ). Finally, the STD-TOCSY spectrum in Figure 5B shows the amino acid Lys from the peptide p151-180 receiving the highest saturation transferance from heparan sulfate.

\section{Discussion}

It is well established that adhesion of bacteria to target host tissues is required for colonization and subsequent development of disease [15]. Since adherence is a key step in microbial pathogenesis, the use of anti-adhesion therapy and anti-adhesion immunity has emerged as an attractive approach toward the development of new tools to control infectious diseases [16]. In order to develop anti-adhesive drugs, including adhesin-based vaccines, a detailed understanding of the mechanisms by which microorganisms initiate host cell colonization is necessary. It has been reported that Hlp is a pivotal adhesion molecule in the context of mycobacteria interaction with host cells. It was initially described as a laminin-binding protein whose function was to mediate $M$. leprae adhesion to Schwann cells in conjunction with PGL-I, another laminin-binding molecule present on the surface of $M$. leprae $[6,7,17]$. Later on, the capacity of Hlp to bind heparin/ heparan sulfate became evident along with the relevance of this interaction in the context of $M$. tuberculosis attachment to respiratory epithelial cells and the potential involvement of this protein in the initial events of host colonization $[8,9,12]$.

Due to the emergence of Hlp as a key component in mycobacterial pathogenesis, a detailed analysis of the molecular regions involved in the interaction with extracellular matrix components was initiated. The first investigation in this direction reported that the region between Thr31 and Phe50 was responsible for the interaction of Hlp with heparin [9]. However, we recently showed that a fragment of the protein corresponding to the last 91 amino acids was additionally able to bind heparan sulfate [12]. To further define the heparan sulfate-binding sites of Hlp in the present study, a panel of 30-mer synthetic peptides 


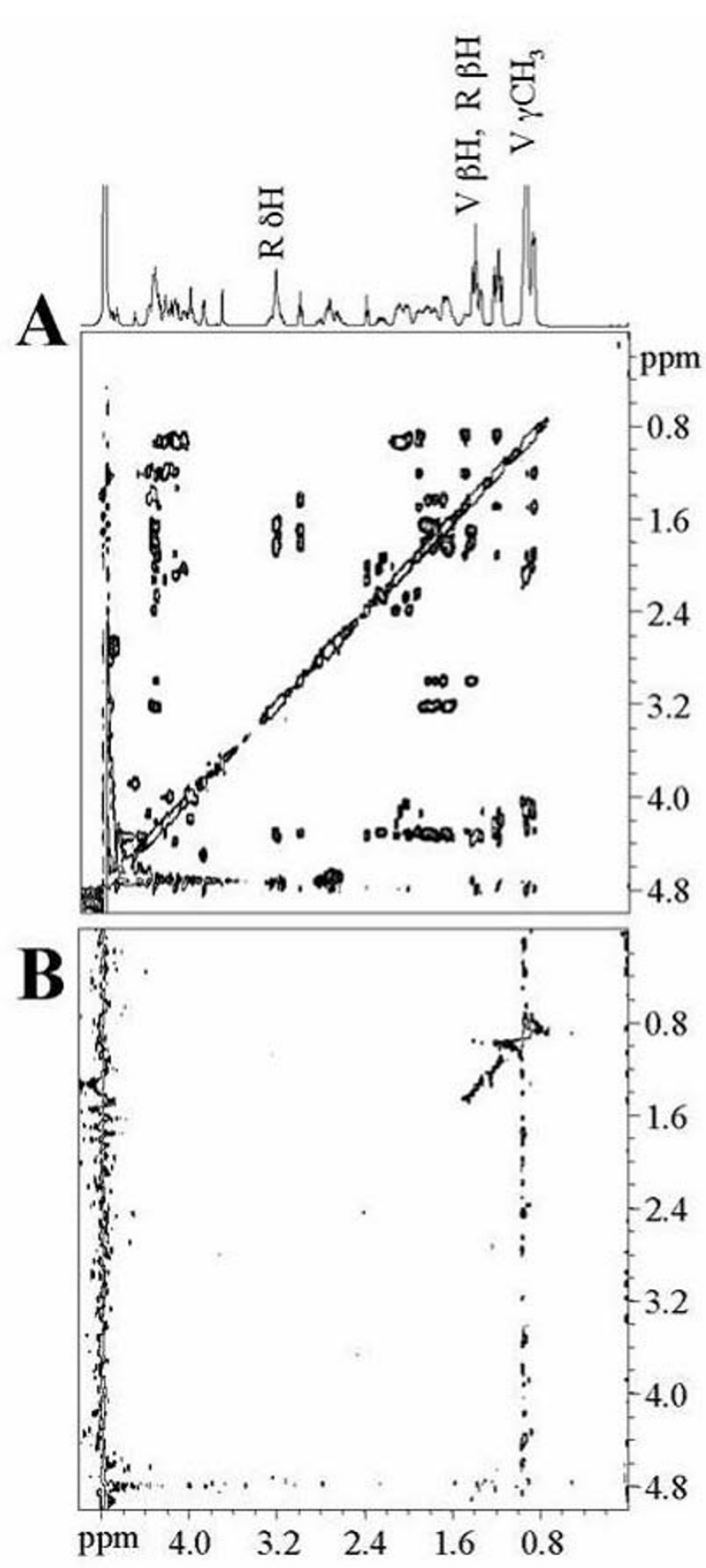

Figure 3

STD-TOCSY of p I 6-45 in presence of heparan sulfate. (A) Reference TOCSY spectrum of pl6-45 (2 mM) in the presence of heparan sulfate $(10 \mu \mathrm{M})$. (B) STD-TOCSY spectrum. Spectra were recorded in PBS- $\mathrm{D}_{2} \mathrm{O}, \mathrm{pH} 7.6,25^{\circ} \mathrm{C}$ with mixing time of $66 \mathrm{~ms}, 32$ scans per $t \mathrm{l}$ increment. 200 increments were collected in an interlaced mode for on or off pre-saturation. derived from the entire sequence of this adhesin was used. Three distinct assays were employed to map the regions of Hlp/LBP involved with heparin/heparan sulfate interaction: solid phase assays in microplates, heparin-Sepharose affinity chromatography, and NMR. The results obtained indicate that Hlp interacts with heparin/heparan sulfate in two distinct regions: one located at the $\mathrm{N}$-terminal half of the protein between residues 31 and 60, and the other corresponding to the entire C-terminal half of the protein.

The features of Hlp heparan sulfate-binding regions herein defined are typical of heparin-binding consensus sequences. As such, they were expected to interact with GAGs (for review, see [18]. The definition of the first site was based on the capacity of peptides p31-60 and p4675 to bind heparin and heparan sulfate using three different assays. These overlapping peptides share the QRRRAAR sequence (residues 52 to 59) that fits perfectly into the heparin-binding consensus XBBBXXB sequence (where $\mathrm{X}$ is an hydropathic amino acid and $\mathrm{B}$ is a basic residue) previously defined by Cardin and Weintraub [18]. NMR experiments confirmed that p31-60 and p46-75, but not p16-45, were able to bind heparan sulfate. Moreover, peptide p31-60 was also able to bind tightly to a heparin-agarose column with elution only occurring at high salt concentrations.

A second GAG-binding region was characterized at the Hlp C-terminal. The 30-mer synthetic peptides p91-120, p106-135, p121-150, p136-165, p151-180, p166-195, and the 20-mer peptide p181-200 covering the C-terminal region of M. leprae Hlp were also able to bind heparin/ heparan sulfate in solid phase assays. Two of these peptides, p136-165 and p151-180, were also tested for their capacity to bind heparin and heparan sulfate in affinity chromatography and NMR, respectively. As a result, their GAG-binding activity was confirmed. All peptides of this region are rich in positively charged residues (from 7 to 11 residues per peptide, mainly Lys), which occur singly or in clusters of two, mostly intercalated with Ala/Val residues. This same spacing pattern of basic amino acids has been found in several heparin-binding domains and seems to facilitate formation of ion pairs with spatially-defined sulfo- or carboxyl-groups in GAGs [19].

Direct NMR observation of the side chain proton resonances that are perturbed upon heparin binding has proven to be a powerful method of identifying the amino acids involved in protein-GAG interaction [20]. However, to our knowledge, this is the first time that STD-NMR has been applied to study the interaction of a ligand (a synthetic peptide) with a nonproteic macromolecule (heparan sulfate). Analysis of the interaction of p31-60, p46-75, p136-165, and p151-180 with heparan sulfate by STD-NMR led the way to identifying Arg, Val, Thr, Phe, 


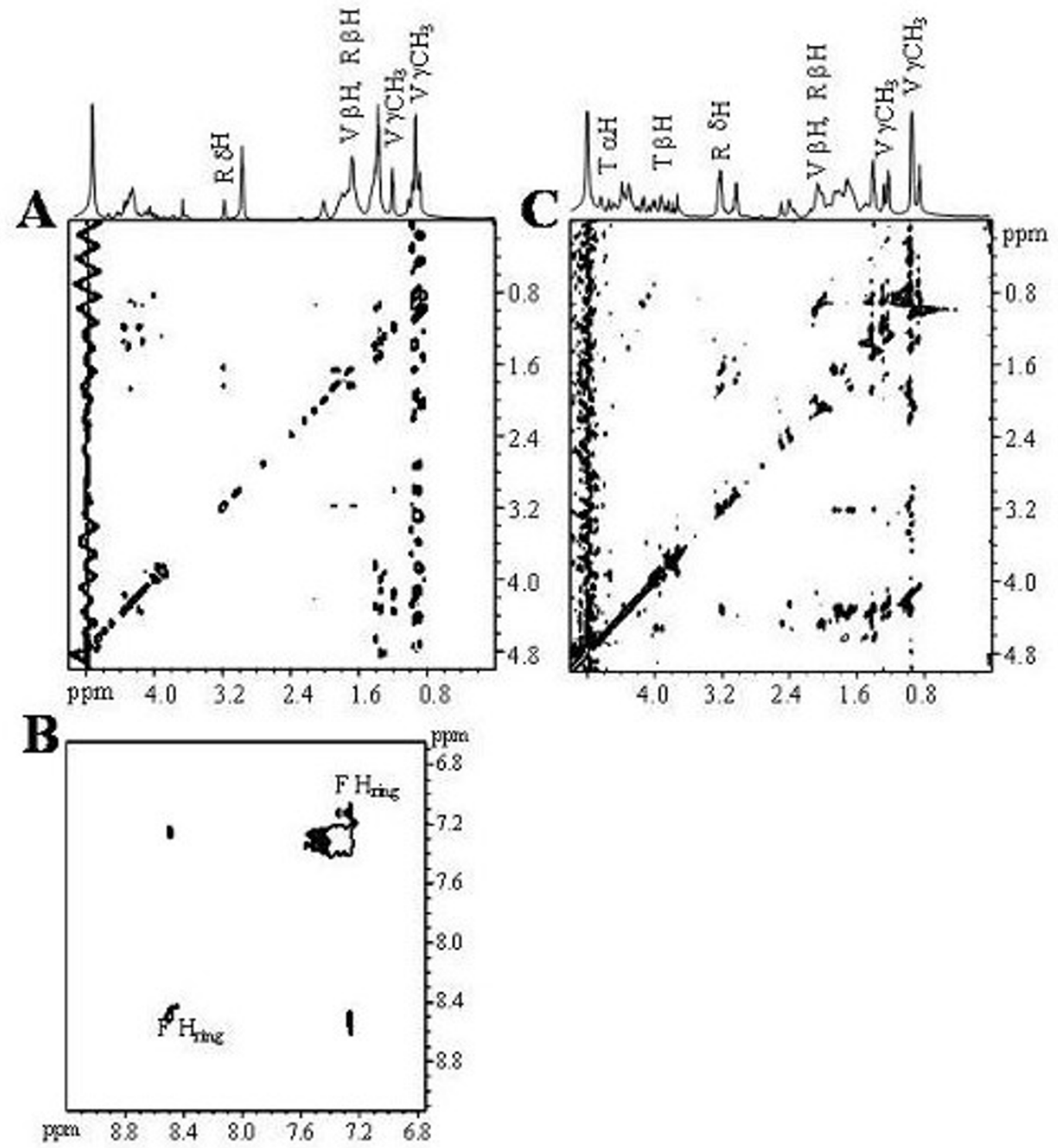

Figure 4

Association of peptides p3 I-60 and p46-75 with heparan sulfate. (A) STD-TOCSY of p3I-60 (2 mM) in the presence of heparan sulfate (10 $\mu \mathrm{M})$. (B) STD-TOCSY spectrum of the aromatic region. (C) STD-TOCSY of p46-75 (2 mM) in the presence of heparan sulfate $(10 \mu \mathrm{M})$. Spectra were recorded as in Figure 3.

Lys, and Ile as the amino acid residues directly involved in Hlp-GAG interaction.

The heparin-binding regions for $M$. leprae Hlp herein described only coincide partially with the one previously reported in M. bovis Hlp (so-called MDP1) [9]. These authors indicated that the sequence between Thr31 and Phe50 was the only heparin-binding site present in MDP1, excluding the cluster of Arg53, Arg54, Arg55, and Arg57 as well as the heparin-binding C-terminal domain of the protein. Their finding was based solely on solid phase assays in microplates using 20-mer synthetic peptides covering the entire length of the protein; and no additional experiments based on different techniques were performed to confirm these results. Moreover, the discrepancy between the Hlp heparin-binding sites cannot be explained by the fact that the Hlp proteins analyzed in both studies originated from different mycobacterial species. As shown in Figure 6, M. leprae and M. bovis BCG Hlp are $84 \%$ identical in their amino acid 


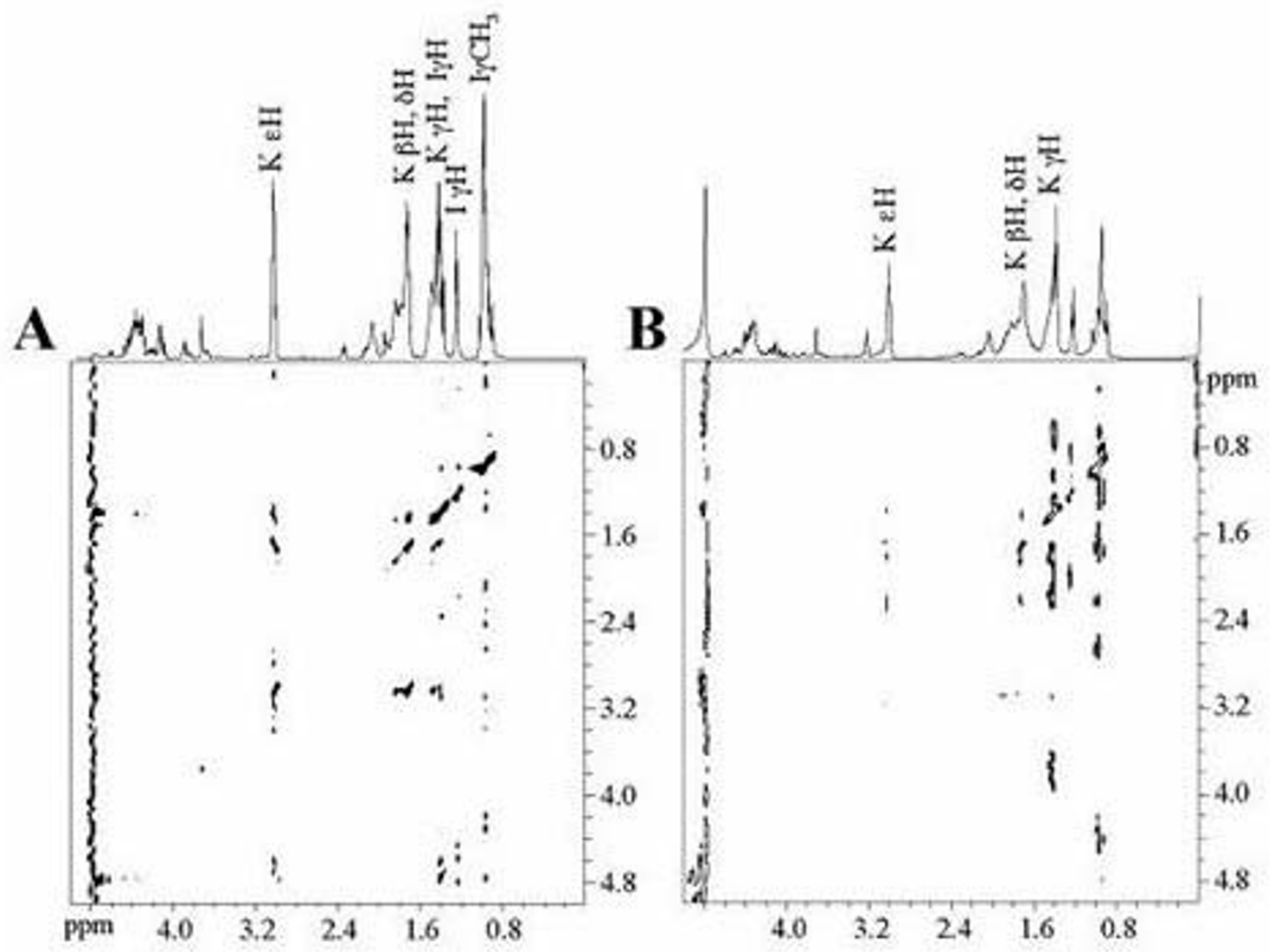

Figure 5

Association of peptides p I36-165 and p I5 I-I80 with heparan sulfate. (A) STD-TOCSY of p/36-165 (2 mM) in association with heparan sulfate $(100 \mu \mathrm{g})$. (B) STD-TOCSY of pI5I-I80 $(2 \mathrm{mM})$ in the presence of heparan sulfate $(10 \mu \mathrm{M})$. Spectra were recorded as in Figure 3.

sequences. Actually, a multiple sequence alignment shows that the N-terminal heparin-binding region described in this study in addition to the one defined by Aoki et al [9] are conserved in all mycobacterial Hlp homologues sequenced to date (data not shown). Variations in Hlp sequences among mycobacterial homologues are mostly located at the C-terminal region even though the features recognized as important for heparin binding seem to be preserved across the species.

In summary, based on this study and previous observations $[9,12]$, we propose that there are two distinct heparan sulfate-binding regions in Hlp: region I, from Thr31 to Ala60 and region II, spanning Lys103 to Lys200 (Figure 6). The identification of Arg in region I and Lys in region II confirms the critical participation of positively charged residues and electrostatic forces in mediating GAG-protein interaction. Moreover, NMR observations showed the direct involvement of Val, Thr, and Phe in region I and Ile in region II, indicating that specific nonionic interactions also take part in Hlp-heparan sulfate binding. As has been observed in other GAG-protein interactions, it is almost certain that these residues interact with $\mathrm{N}$-acetyl and hydroxyl groups in heparan sulfate through hydrophobic interactions and hydrogen bonding, respectively, [18].

Reinforcing the role of the highly positive C-terminal domain in the interaction of Hlp with heparin/heparan sulfate, the heparin binding hemagglutinin (HBHA), another adhesin implicated in the interaction of mycobacteria with epithelial cells [21], also contains lysine-rich 
region I

HIP/LBP Mle MNKAEL IDVLTQKLLSDRRQATAAVENVVD I VRAVHKGDSVT I TGFGVFEQRRRAARVARNPRTGETVKVKPTS 75 MDP1 Mtb MNKAEL I DVLTQKLGSDRRQATAAVENVVDI I VRAVHKGDSVT I TGFGVFEQRRRAARVARNPRTGETVKVKPTS 75

HIP/LBP Mle VPAFRPGAQFKAVVAGAQR̈LPLEGPAVKRGVATSAAKKAAIKKAPVKKALAKKAATKAPAKKAVKAPAKKITTAV 150 MDP1 Mtb VPAFRPGAQFKAVVSGAQRLPAEGPAVKRGVGASAAKKVAKKAPAKKATKAAKKAATKAPARKAATKAPAKKAAT 150 region II

HIP/LBP Mle KVPAKKATKVVKKVAAKAPVRKATTRALAKKAAVKKAPAKKVTAAKRGRK . . . . . . . . . .

MDP1 Mtb KAPAKKAVKATKSPAKKVTKAVKKTAVKASVRKAATKAPAKKAAAKRPATKAPAKKATARRGRK 214

HBHA HS binding site 160 KKAAPAKKAAPAKKAAP AKK AAAKKAP AKKAAAKKVTQK 199

\section{Figure 6}

Protein sequence alignment of HIp from M. leprae, and MDPI and HBHA from M. tuberculosis. The sequence of HIP and MDPI surrounded by the black straight-lined box corresponds to the heparin-interacting region (region I) proposed in this study. The sequence underlined by a red line represents the other heparin-interacting region (region II). The heparin-binding domain of $M$. tuberculosis HBHA is also shown on the bottom. The sequence alignment was prepared via the Jalview Java Alignment Editor version 2.2 [26].

motifs in the C-terminal domain (from Lys161 to Lys199 Figure 6) that have been shown to mediate bacterial adherence via interaction with heparan sulfate-containing proteoglycans [22,23]. HBHA appears, however, to interact with heparin/heparan sulfate more weakly than Hlp [9], suggesting it plays a secondary role in adhesion. Indeed, as shown in this study, Hlp displays an expanded C-terminal GAG-binding domain and an additional heparin-binding region at the $\mathrm{N}$-terminal domain when compared to HBHA, which may explain the higher affinity of Hlp to GAGs (Figure 6).

\section{Conclusion}

The results obtained indicate that Hlp interacts with heparin/heparan sulfate in two distinct regions: one located at the N-terminal half of the protein between residues 31 and 60, and the other corresponding to the entire C-terminal half of the protein. Both heparan sulfate-binding regions are preserved in all mycobacterial Hlp homologues that have been sequenced, suggesting important but possibly divergent roles for this surface-exposed protein in both pathogenic and saprophic species. Due to the emergence of Hlp as a key component in mycobacterial pathogenesis, and the potential involvement of this protein in the initial events of host colonization, a detailed analysis of the molecular regions involved in the interaction with extracellular matrix components may contribute to the development of new prophylaxis and therapeutic interventions in mycobacterial diseases based on this adhesin.

\section{Methods}

\section{M. leprae Recombinant HIp and Peptides}

Recombinant (r) M. leprae Hlp was obtained, as previously described [7]. Twelve 30-mer peptides, overlapping by fifteen amino acids and covering Met1 to Ala195 of M. leprae Hlp and one 20-mer peptide, corresponding to Lys 181 to Lys 200 of the protein, were synthesized by using solid-phase pin technology (Mimotopes, San Diego, CA, USA). Each peptide was dissolved in distilled water at a concentration of $10 \mathrm{mg} / \mathrm{mL}$ and stored frozen at $-20^{\circ} \mathrm{C}$ until use.

\section{Solid-phase binding assays}

Wells of a 96-well of polystyrene microtiter-plates (Corning, New York, NY, USA) were coated with $50 \mu \mathrm{L}$ of Hlp $(0.1 \mu \mathrm{M})$ or synthetic peptides $(0.65 \mu \mathrm{M})$ in $0.1 \mathrm{M}$ carbonate buffer $\mathrm{pH}$ 9.6. Plates were incubated overnight at $4^{\circ} \mathrm{C}$. The wells were then washed with $10 \mathrm{mM}$ of phosphate buffer pH 7.2 and blocked for 2 h with $200 \mu \mathrm{L}$ of phosphate buffer-2\% bovine serum albumin (BSA) at room temperature. Upon washing with phosphate buffer/ $0.05 \%$ Tween $20,50 \mu \mathrm{L}$ of 25 or $50 \mu \mathrm{g} / \mathrm{mL}$ of biotinylated heparin (Sigma) or $10 \mu \mathrm{g} / \mathrm{mL}$ of heparan sulfate (Sigma) in phosphate buffer with increasing $\mathrm{NaCl}$ concentration $(0,125,200$ and $400 \mathrm{mM})$ were added to the wells and incubation was performed at room temperature for $2 \mathrm{~h}$. The wells were rinsed with phosphate buffer/Tween 20 and incubated with $50 \mu \mathrm{L}$ of streptavidin-peroxidase (Pierce, Rockford, IL, USA) at $0.5 \mu \mathrm{g} / \mathrm{mL}$. Peroxidase activity was revealed with hydrogen peroxide and O-phenylenediamine (OPD). The reaction was stopped with $\mathrm{HCl}$ and read at $490 \mathrm{~nm}$ using an automatic microplate scanning spectrophotometer (SpectraMAX 190; Molecular Devices Corp, Sunnyvale, CA, USA). 


\section{NMR Experiments}

Peptides p16-45, p31-60, p46-75, p136-165, p151-180 ( $2 \mathrm{mM}$ final concentration), and heparan sulfate $(10 \mu \mathrm{M})$ were dissolved in deuterated phosphate buffered saline (PBS), pH 7.6 (not correct for isotope effects). NMR spectra were obtained at a temperature probe of $25^{\circ} \mathrm{C}$ on a Bruker DMX 600 equipped with a 5-mm triple resonance probe.

\section{Saturation Transfer Difference (STD)}

TOCSY-STD spectra correspond to a modified TOCSY sequence $[24,25]$. Spectra were recorded with a mixing time of $66 \mathrm{~ms}, 32$ scans per $t_{1}$ increment with pre-saturation on or off for $2 \mathrm{~s}$. The on-resonance irradiation at the heparan sulfate was applied at a chemical shift of $5.5 \mathrm{ppm}$ (where protein signals from all peptides were not observed). Off-resonance irradiation was applied at 30 ppm (where no signals were observed). Samples containing only the peptides were used as controls and did not show any STD effect, since the resulting diference spectrum did not contain any signal for the peptide. Two hundred $t_{2}$ increments were collected in an interlaced mode after every on- and off-irradiation spectra to minimize artifacts arising from temperature and magnet instability. Prior to subtraction, both spectra were identically processed and phased. The acquisition time for the twodimensional experiments was typically $16 \mathrm{~h}$. The spectra were apodized with a square cosine bell function in both dimensions and zero-filled twice.

\section{Authors' contributions}

MIP, ART, CSL and CAMS performed the experiments, the data analysis, interpreted the results and drafted the manuscript. MCVP, JOP and RMB participated in the design of the study, in evaluation of the results and in revision of the manuscript. THMO and LMP discussed the results and critically read the manuscript. All authors read and approved the final manuscript.

\section{Acknowledgements}

This study was supported by PAPES-FIOCRUZ. M.I.P and C.S.L. were recipients, respectively, of a fellowship awarded by the Coordenação de Aperfeiçoamento de Pessoal de Ensino Superior (CAPES) and the Oswaldo Cruz Insititute. C.A.M.S. was a recipient of a fellowship from the Conselho Nacional de Desenvolvimento Científico e Tecnológico (CNPq). We would also like to thank Judy Grevan for editing the text.

\section{References}

I. Leprosy WHO website [http://www.who.int/lep]

2. Tuberculosis WHO website [http://www.who.int/tb]

3. Fine PE: Primary prevention of leprosy. Int J Lepr Other Mycobact Dis 1996:S44-49.

4. Vidal Pessolani MC, Marques MA, Reddy VM, Locht C, Menozzi FD: Systemic dissemination in tuberculosis and leprosy: do mycobacterial adhesins play a role? Microbes Infect 2003, 5:677-684

5. Antia NH: Leprosy a disease of the Schwann cell. Lepr India 1982, 54:599-604.
6. Shimoji $Y, N g$ V, Matsumura $K$, Fischetti VA, Rambukkana A: A 2IkDa Surface protein of Mycobacterium leprae binds peripheral nerve laminin-2 and mediates Schwann cell invasion. Proc Natl Acad Sci USA 1999, 96:9857-9862.

7. Marques MA, Mahapatra S, Nandan D, Dick T, Sarno EN, Brennan PJ, Vidal Pessolani MC: Bacterial and Host-derived cationic proteins bind alpha2-laminins and enhance Mycobacterium leprae attachment to human Schwann cells. Microbes Infect 2000, 2:|407-|4|7.

8. Pethe K, Puech V, Daffe M, Josenhans C, Drobecq H, Locht C, Menozzi FD: Mycobacterium smegmatis laminin-binding glycoprotein shares epitopes with Mycobacterium tuberculosis heparin-binding haemagglutinin. Mol Microbiol 200I, 39:89-99.

9. Aoki K, Matsumoto S, Hirayama $Y$, Wada T, Ozeki $Y$, Niqui M, Domenech P, Umemori K, Yamamoto S, Mineda A, Matsumoto M, Kobayashi K: Extracellular mycobacterial DNA-binding protein I participates in mycobacterium-lung epithelial cell interaction through hyaluronic acid. I Biol Chem 2004, 279:39798-39806.

10. Prabhakar S, Annapurna PS, Jain NK, Dey AB, Tyagi JS, Prasad HK: Identification of an immunogenic histone-like protein (HLPMt) of Mycobacterium tuberculosis. Tuber Lung Dis 1998, 79:43-53.

II. Furugen M, Matsumoto S, Matsuo T, Matsumoto M, Yamada T: Identification of the mycobacterial DNA-binding protein I region which suppresses transcription in vitro. Microb Pathog 200I, 30:129-138

12. Soares de Lima C, Zulianello L, Marques MA, Kim H, Portugal MI, Antunes SL, Menozzi FD, Ottenhoff TH, Brennan PJ, Pessolani MC: Mapping the laminin-binding and adhesive domain of the cell surface-associated HIp/LBP protein from Mycobacterium leprae. Microbes Infect 2005, 7:1097-109.

13. Mayer M, Meyer B: Group epitope mapping by saturation transfer difference NMR to identify segments of a ligand in direct contact with a protein receptor. J Am Chem Soc 200I, 123:6108-6II7.

14. Todeschini AR, Dias WB, Girard MF, Wieruszeski JM, Mendonca-Previato L, Previato JO: Enzymatically inactive trans-sialidase from Trypanosoma cruzi binds sialyl and beta-galactopyranosyl residues in a sequential ordered mechanism. J Biol Chem 2004, 279:5323-5328

15. Wilson M, MacNab R, Henderson B: Bacterial adhesion as a virulence mechanism. In Bacterial Disease Mechanisms: An Introduction to Cellular Microbiology Ist edition. Cambridge: Cambridge University; 2002:353-404

16. Ofek I, Hasty DL, Sharon N: Anti-adhesion therapy of bacterial diseases: prospects and problems. FEMS Immunol Med Microbiol 2003, 38: $|8|-|9|$.

17. Ng V, Zanazzi G, Timpl R, Talts JF, Salzer JL, Brennan PJ, Rambukkana $A:$ Role of the cell wall phenolic glycolipid- $I$ in the peripheral nerve predilection of Mycobacterium leprae. Cell 2000, 103:5II-524.

18. Capila I, Linhardt RJ: Heparin-protein interactions. Chem Int Ed Engl 2002, 4I:39I-4I2.

19. Hileman RE, Fromm JR, Weiler JM, Linhardt RJ: Glycosaminoglycan-protein interactions: definition of consensus sites in glycosaminoglycan binding proteins. Bioessays 1998, 20:156-167.

20. Mayo KH, llyina E, Roongta $\mathrm{V}$, Dundas M, Joseph J, Lai CK, Maione T, Daly TJ: Heparin binding to platelet factor-4. An NMR and site-directed mutagenesis study: arginine residues are crucial for binding. Biochem 1995, 3 I 2:357-365.

21. Menozzi FD, Rouse JH, Alavi M, Laude-Sharp M, Muller J, Bischoff R, Brennan MJ, Locht C: Identification of a heparin-binding hemagglutinin present in mycobacteria. J Exp Med 1996, 184:993-I00I.

22. Delogu G, Brennan MJ: Functional domains present in the mycobacterial hemagglutinin, HBHA. J Bacteriol 1999 , 181:7464-7469.

23. Pethe K, Aumercier M, Fort E, Gatot C, Locht C, Menozzi FD: Characterization of the heparin-binding site of the mycobacterial heparin-binding hemagglutinin adhesin. J Biol Chem 2000, 275: 14273-14280.

24. Bax A, Davis DG: MLEV-I7 based two-dimensional homonuclear magnetization transfer spectroscopy. J Magn Reson 1985, 65:355-360 
25. Griesinger C, Otting G, Wuthrich K, Ernst RR: Two-dimensional correlation of connected NMR transitions. JACS 1988, I I 0:7870-72.

26. Clamp M, Cuff J, Searle SM, Barton GJ: The Jalview Java alignment editor. Bioinformatics 2004, 20:426-427.

Publish with Bio Med Central and every scientist can read your work free of charge

"BioMed Central will be the most significant development for disseminating the results of biomedical research in our lifetime. " Sir Paul Nurse, Cancer Research UK

Your research papers will be:

- available free of charge to the entire biomedical community

- peer reviewed and published immediately upon acceptance

- cited in PubMed and archived on PubMed Central

- yours - you keep the copyright

Submit your manuscript here:

http://www.biomedcentral.com/info/publishing_adv.asp
BioMedcentral 